\title{
Exertional hypotension in thoracic spinal cord injury: case report
}

\author{
M L King MD, D M Freeman RN, J T Pellicone MD, E R Wanstall RN, L D Bhansali \\ MD
}

Helen Hayes Hospital, Route 9W, West Haverstraw, New York 10993, USA.

\begin{abstract}
Exertional hypotension is well described in quadraplegics, but there are few descriptions of this hemodynamic response in paraplegics or of treatment modalities to correct this condition. We describe a patient with a complete T3-4 spinal cord lesion who repeatedly demonstrated symptomatic hypotension with wheelchair sports and arm ergometry. We used gas exchange analysis and exercise echocardiography to delineate the mechanism for hypotension. These results enabled us to develop a simple treatment plan consisting of abdominal binding and elastic stockings to avoid recurrent symptoms.
\end{abstract}

Key words: thoracic spinal cord injury; paraplegia; exercise test; oxygen consumption, echocardiography.

\section{Introduction}

High level SCI patients may demonstrate a fall in blood pressure with exercise, related to decreased vasomotor tone and cardiac output, ${ }^{1}$ but this has not been systematically described, particularly for paraplegics. Exercise echocardiography has been used to study exertional hypotension in healthy men and those with coronary artery disease. ${ }^{2.3}$ Coupled with gas exchange analysis, exercise echocardiography is an ideal clinical tool to investigate hemodynamic changes with exercise in SCI patients but has yet to be applied in this clinical setting. In addition, testing can easily be repeated to evaluate a variety of therapeutic maneuvers. We have used these modalities in a young T3-4 SCI patient to delineate the cause of his symptomatic exertional hypotension and to design an appropriate treatment plan.

\section{Case history}

We describe a 34 year old male with a traumatic complete T3-4 spinal cord injury in 1977 who underwent cardiac evaluation prior to enrolling in a functional electrical stimulation bicycle ergometry program. He was taking no vasoactive medications and, except for his spinal cord injury, was in good health. He had no history of cardiac risk factors or symptoms but reported near syncope with exercise, primarily with wheelchair basketball but not with wheelchair racing. The symptoms were generally relieved with bending over with his head in a dependent position and were worse in warm weather. Cardiac examination was normal, with resting pulse $61 \mathrm{bpm}$, blood pressure $110 / 70$, and no murmurs.

Electrocardiogram revealed normal sinus rhythm with no abnormalities and resting echocardiography revealed normal valves, wall motion and function. Left ventricular wall thickness and wall motion were also normal and there were no signs of outflow tract obstruction. Left ventricular volume and function from $M$ mode echocardiography in the supine and seated positions are shown in Table $\mathbf{I}$.

\section{Methods}

Arm ergometry was performed using a Monark cycle ergometer mounted at chest level on a table. A continuous protocol was used, with 2 minute stages and 12.5 watt increments. Pedal speed was held constant at $50 \mathrm{rpm}$, and exercise was terminated by the patient for maximal symptoms of arm fatigue, dyspnea or presyncope.

Heart rate, rhythm, and ST segments were monitored continuously using Quinton Q3000 exercise electrocardiography. 
Table I Left ventricular volumes and dimensions by M mode echocardiography

\begin{tabular}{lcccccc}
\hline $\begin{array}{l}\text { Patient } \\
\text { position }\end{array}$ & $\begin{array}{c}\text { LVDV } \\
(\mathrm{ml})\end{array}$ & $\begin{array}{c}\text { LVSV } \\
(\mathrm{ml})\end{array}$ & $\begin{array}{c}\text { SV } \\
(\mathrm{ml})\end{array}$ & $\begin{array}{c}\text { HR } \\
(\mathrm{bpm})\end{array}$ & $\begin{array}{c}\text { CO } \\
(\mathrm{L} / \mathrm{min})\end{array}$ & $\begin{array}{c}\text { LVEF } \\
(\%)\end{array}$ \\
\hline Supine & 74 & 14 & 60 & 60 & 3.6 & 81 \\
Seated & 51 & 13 & 38 & 93 & 3.5 & 75 \\
\hline
\end{tabular}

LVDV = left ventricular end diastolic volume LVSV = left ventricular end systolic volume $\mathrm{SV}=$ stroke volume

Twelve lead EKGs were obtained at one minute intervals. Blood pressure was taken pre-exercise, during the final 15 to 30 seconds of each stage, and for 7 minutes post exercise. Blood pressures were measured with the subject dropping one arm and the technician assisting to maintain constant pedal speed. This blood pressure protocol has been used successfully in the cardiology literature ${ }^{4.5}$ as well as in our laboratory. ${ }^{6}$

Gas exchange analysis was monitored continuously by the Medical Graphics System 2001, using breath-by-breath analysis of $\mathrm{VO} 2, \mathrm{VCO} 2$, oxygen pulse (VO2/HR) and VE.

$M$ mode and 2D echocardiography were done in the seated position both immediately prior to exercise and within 90 seconds post exercise, using the ATL Ultramark 4. Measurements of left ventricular dimensions and gross analysis of wall motion were done by 2 different observers, with good interobserver agreement. $M$ mode echocardiography measurements of the left ventricle have been shown to be accurate and reproducible in patients with normal wall motion. ${ }^{7,8}$

Two baseline arm argometry tests with gas exchange analysis were performed to demonstrate reproducibility of this patient's blood pressure response to exercise. Following this, testing was repeated with and without each of the following variables: no abdominal binder or elastic stockings, abdominal binder plus elastic stockings, abdominal binder alone, and elastic stockings alone.

Thigh length nylon TED antiembolism stockings and/or a Camp model 337 abdominal binder were used for the exercise test variables listed above. The abdominal
$\mathrm{HR}=$ heart rate

$\mathrm{CO}=$ cardiac output

LVEF = left ventricular ejection fraction

binder was elastic with velcro closures, applied circumferentially just below the anterior superior iliac spines and extended upward to the inferior aspect of the anterior rib cage just below T10.

\section{Results}

During his initial arm ergometry test, the patient reached a maximum workload 50 watts, heart rate $193 \mathrm{bpm}, \mathrm{VO} 215 \mathrm{ml}$ $\mathrm{O} 2 / \mathrm{kg} / \mathrm{min}$, and $\mathrm{VE} 50.9 \mathrm{~L} / \mathrm{min}$. Exercise was discontinued when blood pressure progressively dropped from $120 / 70$ during the first stage of exercise to $90 / 50$ at termination of exercise. There were no ST-T changes or arrythymias with exercise and post exercise examination revealed no respiratory or cardiac signs.

The test was repeated approximately 2 weeks later. During this test, he reached a maximum workload 62.5 watts, heart rate $184 \mathrm{bpm}, \mathrm{VO} 216 \mathrm{ml} \mathrm{O} 2 / \mathrm{kg} / \mathrm{min}$, and VE $73.1 \mathrm{~L} / \mathrm{min}$. Exercise was terminated when symptomatic hypotension developed, with systolic blood pressure of $50 \mathrm{mmHG}$ and presyncopal symptoms. Blood pressure returned to baseline by 3 minutes post exercise. Again, there were no electrocardiographic findings or changes in examination.

Exercise data during each of the therapeutic maneuvers is shown in Figures 1-4. The increase in oxygen consumption with workload is illustrated in Figure 1 and did not vary significantly with exercise condition. However, Figures 2, 3, and 4 demonstrate a significant difference in blood pressure, heart rate, and oxygen pulse at submaximal workloads, when exercise with both binder and stockings is compared to the other exercise conditions. Systemic blood pressure and oxygen pulse increased 


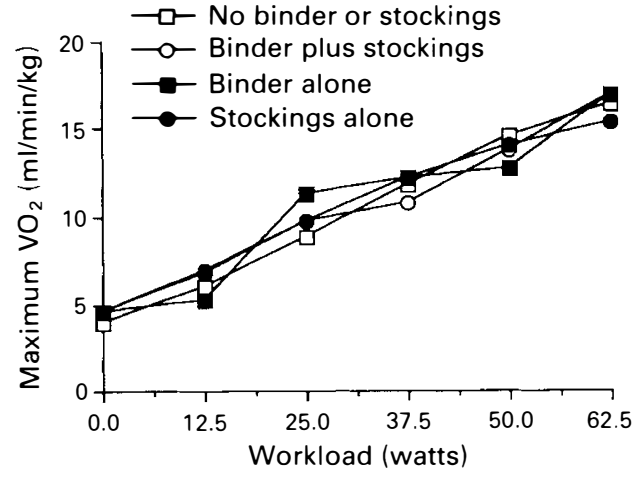

Figure 1 Increase in $\mathrm{VO}_{2}$ with workload with each of the exercise conditions.

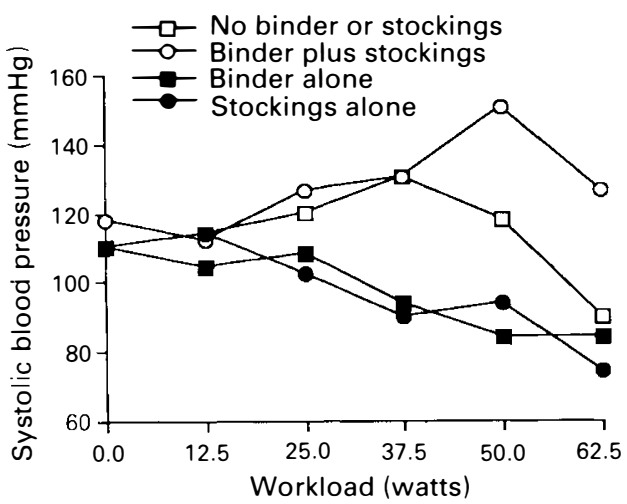

Figure 2 Change in systolic blood pressure with workload with each of the exercise conditions.

significantly above the resting level only when the patient wore both the abdominal binder and the elastic stockings during exercise (Figs 2 and 4). In fact, the patient stated that this was the first time that his face had felt warm and flushed with exercise since his spinal cord injury.

Left ventricular volumes, stroke volume, cardiac output, and ejection fraction measured by $\mathbf{M}$ mode echocardiography are shown in Table II. The heart rate used to calculate output was the post exercise heart rate at the time the echocardiography was performed. Although cardiac output consistently rose with exercise, stroke volume and left ventricular ejection fraction rose significantly only during the binder plus stockings trial.

Table III shows arterial blood pressure, peripheral vascular resistance, end expirat-

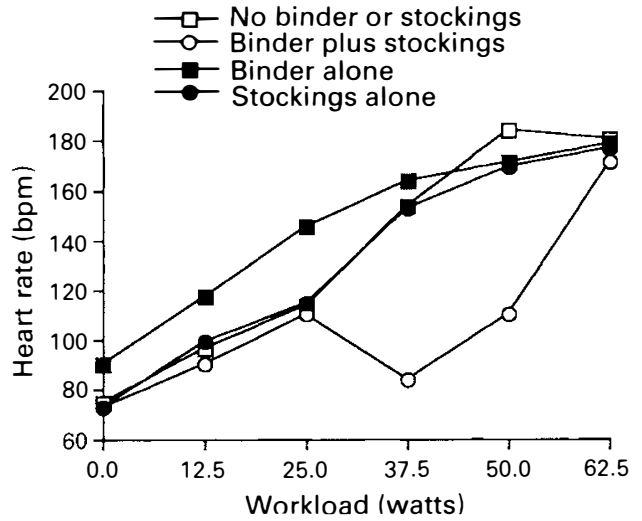

Figure 3 Change in heart rate with workload with each of the exercise conditions.

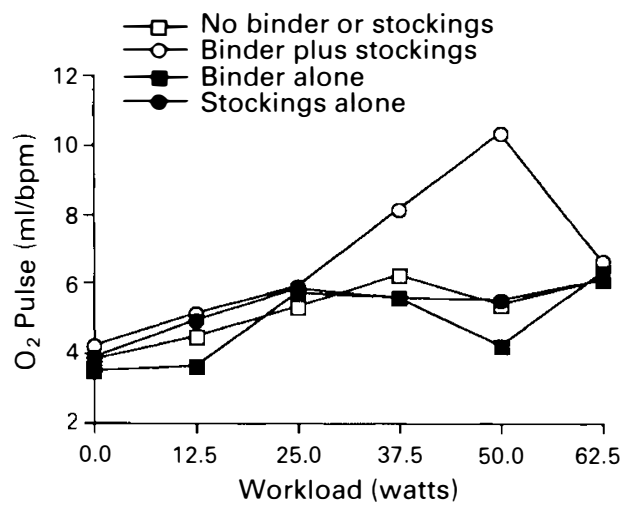

Figure 4 Change in $\mathrm{O}_{2}$ pulse with workload with each of the exercise conditions.

ory $\mathrm{CO} 2$, and $\mathrm{VCO} 2$ at rest and at peak exercise with each of the maneuvers. Peripheral vascular resistance decreased during all exercise conditions, with the smallest percent decrease during the binder plus stocking trial. End tidal $\mathrm{CO} 2$ decreased with all conditions except the binder plus stockings, despite consistent increases in $\mathrm{VCO} 2$ with exercise.

\section{Discussion}

We have shown how a simple therapeutic maneuver such as an abdominal binder and elastic stockings can be used to correct symptomatic exertional hypotension in a paraplegic patient with a high level injury. Using exercise echocardiography and gas 
Table II Left ventricular volumes obtained by $\mathrm{M}$ mode echocardiography pre and post exercise with different exercise conditions

\begin{tabular}{lcccccc}
\hline $\begin{array}{l}\text { Exercise } \\
\text { condition }\end{array}$ & $\begin{array}{c}\text { LVDV } \\
(\mathrm{ml})\end{array}$ & $\begin{array}{c}\text { LVSV } \\
(\mathrm{ml})\end{array}$ & $\begin{array}{c}\text { SV } \\
(\mathrm{ml})\end{array}$ & $\begin{array}{c}\text { HR } \\
(\mathrm{bpm})\end{array}$ & $\begin{array}{c}\text { CO } \\
(\mathrm{L} / \mathrm{min})\end{array}$ & $\begin{array}{c}\text { LVEF } \\
(\%)\end{array}$ \\
\hline No binder or stockings & & & & & & \\
Rest & 62 & 11 & 51 & 73 & 3.7 & 82 \\
$\begin{array}{l}\text { Exercise } \\
\text { Binder plus stockings }\end{array}$ & 51 & 11 & 40 & 186 & 7.4 & 78 \\
Rest & 58 & 18 & 40 & 75 & 3.0 & 69 \\
Exercise & 51 & 6 & 45 & 169 & 7.6 & 88 \\
Binder alone & & & & & & \\
Rest & 66 & 18 & 48 & 77 & 3.7 & 73 \\
Exercise & 41 & 10 & 31 & 150 & 4.7 & 76 \\
Stockings alone & & & & & & \\
Rest & 66 & 16 & 50 & 73 & 3.7 & 76 \\
Exercise & 51 & 11 & 40 & 150 & 6.0 & 78 \\
\hline
\end{tabular}

LVDV = left ventricular end diastolic volume

$\mathrm{HR}=$ heart rate

LVSV $=$ left ventricular end systolic volume

$\mathrm{CO}=$ cardiac output

$\mathrm{SV}=$ stroke volume

LVEF $=$ left ventricular ejection fraction

Table III Blood pressure, peripheral vascular resistance, and $\mathrm{CO}_{2}$ parameters at rest and at peak exercise

\begin{tabular}{|c|c|c|c|c|c|c|}
\hline $\begin{array}{l}\text { Exercise } \\
\text { condition }\end{array}$ & $\begin{array}{c}\mathrm{BP} \\
(\mathrm{mmHg})\end{array}$ & $\begin{array}{c}\mathrm{MAP} \\
(\mathrm{mmHg})\end{array}$ & $\begin{array}{l}\text { PVR } \\
\text { (pru) }\end{array}$ & $\begin{array}{c}\Delta \mathrm{PVR} \\
(\%)\end{array}$ & $\begin{array}{c}\mathrm{PETCO}_{2} \\
(\mathrm{mmHg})\end{array}$ & $\begin{array}{c}\mathrm{VCO}_{2} \\
(\mathrm{ml} / \mathrm{min})\end{array}$ \\
\hline \multicolumn{7}{|c|}{ No binder or stockings } \\
\hline Rest & $110 / 70$ & 97 & 26 & & 36 & 260 \\
\hline Exercise & $90 / 40$ & 73 & 10 & 61 & 28 & 896 \\
\hline \multicolumn{7}{|c|}{ Binder plus stockings } \\
\hline Rest & $118 / 80$ & 105 & 35 & & 35 & 308 \\
\hline Exercise & $126 / 40$ & 97 & 13 & 34 & 35 & 1525 \\
\hline \multicolumn{7}{|c|}{ Binder alone } \\
\hline Rest & $110 / 70$ & 97 & 26 & & 30 & 334 \\
\hline Exercise & $84 / 50$ & 73 & 15 & 42 & 24 & 981 \\
\hline \multicolumn{7}{|c|}{ Stockings alone } \\
\hline Rest & $110 / 74$ & 98 & 26 & & 35 & 301 \\
\hline Exercise & $74 / 44$ & 64 & 11 & 58 & 32 & 1061 \\
\hline
\end{tabular}

$\mathrm{BP}=$ blood pressure

MAP $=$ mean arterial blood pressure

$\triangle \mathrm{PVR}=$ percent decrease in PVR with exercise

$\mathrm{PVR}=$ peripheral vascular resistance

$\mathrm{PETCO}_{2}=$ end expiratory carbon dioxide

$\mathrm{VCO}_{2}=$ carbon dioxide production

exchange analysis, we have shown that the cause of this patient's exertional hypotension is decreased vasomotor control related to his spinal cord lesion.
In able bodied individuals, increased sympathetic discharge with exercise constricts capacitance vessels and increases myocardial contractility. These factors allow blood 
pressure to rise with exercise despite a drop in peripheral vascular resistance. ${ }^{2}$

Calculated peripheral vascular resistance did fall during all exercise conditions in this patient, including during the binder plus stocking trial (Table III). However, the percent decrease in PVR was the smallest in the binder plus stockings trial, possibly accounting for the rise in mean arterial blood pressure with exercise in only this condition. Elastic stockings alone had no significant effect on rest or exercise PVR or on the percent change in PVR with exercise, compared to exercise without external compressive garments. The abdominal binder alone lowered the percent decrease in PVR with exercise but was still associated with exertional hypotension. However, adding elastic stockings to the abdominal binder increased the resting PVR and blood pressure, resulting in a lower percent decrease in PVR and a higher end exercise blood pressure.

Gas exchange data was analyzed to find a hypothesis for the marked drop in peripheral vascular resistance with exercise in this patient. Despite an increase in VCO2, end expiratory $\mathrm{CO} 2$ dropped at peak exercise in all conditions except the binder plus stocking trial. Although hyperventilation may have contributed to a decrease in sympathetic tone and therefore a drop in peripheral vascular resistance, it is also possible that the hyperventilation was secondary to the drop in blood pressure rather than a primary phenomenon. Other reasons for a drop in vascular resistance with exercise could include changes in core body temperature, changes in circulating catecholamine levels, or other yet undefined mechanisms.

Stroke volume and oxygen pulse also increased to the expected range for paraplegics ${ }^{9}$ only with the combination of binder and stockings, probably related to changes in vasomotor tone, primarily in capacitance vessels. This is similar to findings by Coutts et al ${ }^{10}$ who reported lower oxygen pulse measurements with exercise in high thoracic compared with lower level spinal cord lesions. Other authors have shown decreased exercise stroke volume in paraplegic compared to able bodied individuals, ${ }^{11.12}$ and one study has suggested that exercise training can improve exercise stroke volume in these patients. ${ }^{13}$ However, none has addressed systemic blood pressure or therapeutic maneuvers to correct exertional hypotension.

Our findings are similar to those using military antishock trouser inflation during standing arm exercise in young able bodied individuals, with the exception of changes in peripheral vascular resistance. ${ }^{14}$ These authors described significant increases in stroke volume, cardiac output, and mean arterial blood pressure as well as decreases in heart rate during exercise with MAST inflation compared to exercise without lower body positive pressure. However, in these subjects, total peripheral resistance did not change. This was attributed to mechanical compression offsetting the exercise-induced vasodilation in active muscles. Although the percent drop in PVR with the binder plus stocking trial was less than that with other exercise conditions in our patient, the mechanical compression by the binder and stockings did not appear to be sufficient to prevent exercise induced vasodilation in our patient.

Exercise echocardiography has been used to study exertional hypotension in apparently healthy males. ${ }^{2}$ These patients were found to have no difference with exercise in a supine compared to seated position, indicating that venous pooling was not playing a significant role. Abnormalities of left ventricular compliance were postulated as the reason for decreased left ventricular end diastolic dimension and ejection fraction with exercise in these patients. If this were the case in our patient we would not expect such a dramatic improvement in blood pressure with the simple maneuver of external lower body compression. Long term follow up of these young able bodied patients with exertional hypotension has unfortunately shown an increased rate of development of overt coronary artery disease, compared to controls. ${ }^{3}$ Although we feel that our patient's primary problem is inadequate vasomotor control due to his spinal cord injury, we also intend to follow him closely in future to determine if coronary artery disease develops. 


\section{Acknowledgements}

This work was undertaken in association with the Helen Hayes Hospital Center for Rehabilitation Technology directed by Martin Ferguson-
Pell, PhD. Funding support was provided in part by the National Institute on Disability and Rehabilitation Research, Grant Number 133G90141. Helen Hayes Hospital is operated by the New York State Department of Health.

\section{References}

1 Glaser RM (1989) Arm exercise training for wheelchair users. Med Sci Sports Exerc 21: S149-157.

2 Fisman EZ, Pines A, Ben-Ari E, Shiner RJ, Shaer S, Kellermann JJ (1989) Left ventricular exercise echocardiographic abnormalities in apparently healthy men with exertional hypotension. Am J Cardiol 63: 81-85.

3 Ben-Ari E, Fisman EZ, Pines A, Dlin R, Kessler G, Kellermann JJ (1990) Significance of exertional hypotension in apparently healthy men: a 8.9 year follow-up. J Cardiopulmon Rehabil 10: 92-97.

4 Balady GJ, Weiner DA, McCabe CH, Ryan TJ (1985) Value of arm exercise testing in detecting coronary artery disease. Am J Cardiol 55: 37-39.

5 Levandoski SG, Sheldahl LM, Wilke NA, Tristani FE, Hoffman MD (1990) Cardiorespiratory responses of coronary artery disease patients to arm and leg cycle ergometry. J Cardiopulmon Rehabil 10: 39-44.

6 King ML, Guarracini M, Lennihan L, Freeman D, Gagas B, Boston A et al (1989) Adaptive exercise testing for patients with hemiparesis. J Cardiopulmon Rehabil 9: 237-242.

7 Feigenbaum H, Popp RL, Wolfe SB, Troy BL, Pombo JF, Haine CL et al (1972) Ultrasound measurements of the left ventricle. Arch Intern Med 129: 461-267.

8 Bhatt DR, Isabel-Jones JB, Villoria GJ, Nakazawa M, Yabek SM, Marks RA et al (1978) Accuracy of echocardiography in assessing left ventricular dimensions and volume. Circulation 57: 699-707.

9 Eriksson P, Lofstrom L, Ekblom B (1988) Aerobic power during maximal exercise in untrained and well-trained persons with quadriplegia and paraplegia. Scand J Rehabil Med 20: 141-147.

10 Coutts KD, Rhodes EC, McKenzie DC (1985) Submaximal exercise responses to tetraplegics and paraplegics. J Appl Physiol 59: 237-241.

11 Kinzer SM, Convertino VA (1989) Role of leg vasculature in the cardiovascular response to arm work in wheelchair-dependent populations. Clin Physiol 9: 525-533.

12 VanLoan MD, McCluer S, Loftin JM, Boileau RA (1987) Comparison of physiological responses to maximal arm exercise among able-bodies, paraplegics and quadriplegics. Paraplegia 25: $397-405$.

13 Davis GM, Shephard RJ (1988) Cardiorespiratory fitness in highly active versus inactive paraplegics. Med Sci Sports Exerc 20: 463-468.

14 NG AV, Hanson P, Aaron EA, Demment RB, Conviser JM, Nagle FJ (1987) Cardiovascular responses to military antishock trouser inflation during standing arm exercise. J Appl Physiol 63: 1224-1229. 